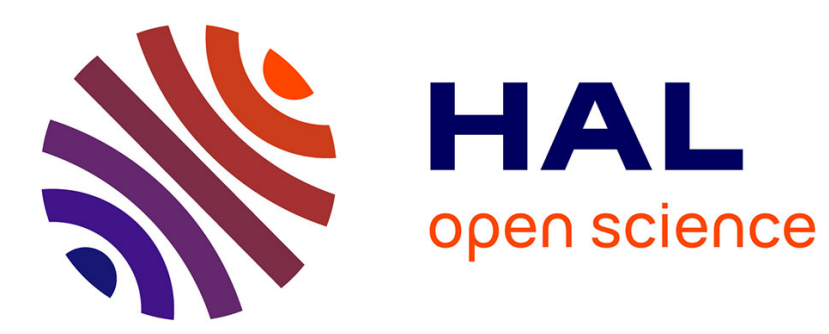

\title{
Dynamic Ductility of Metals
}

E. El-Magd, H. Scholles, H. Weisshaupt

\section{- To cite this version:}

E. El-Magd, H. Scholles, H. Weisshaupt. Dynamic Ductility of Metals. Journal de Physique IV Proceedings, 1997, 07 (C3), pp.C3-349-C3-354. 10.1051/jp4:1997361 . jpa-00255518

\section{HAL Id: jpa-00255518 https://hal.science/jpa-00255518}

Submitted on 1 Jan 1997

HAL is a multi-disciplinary open access archive for the deposit and dissemination of scientific research documents, whether they are published or not. The documents may come from teaching and research institutions in France or abroad, or from public or private research centers.
L'archive ouverte pluridisciplinaire HAL, est destinée au dépôt et à la diffusion de documents scientifiques de niveau recherche, publiés ou non, émanant des établissements d'enseignement et de recherche français ou étrangers, des laboratoires publics ou privés. 
J. PHYS IV FRANCE 7 (1997)

Colloque C3, Supplément au Journal de Physique III d'août 1997

\title{
Dynamic Ductility of Metals
}

\author{
E. El-Magd, H. Scholles* and H. Weisshaupt* \\ RWTH Aachen University of Technology, Department of Materials Science (LFW), Augustinerbach 4, \\ 52056 Aachen, Germany \\ "Rheinmetall Industrie Aktiengesellschaft, Unterlüss, Germany
}

\begin{abstract}
The influence of strain rate on the stress strain curve of the impact tension test is discussed on the basis of the theory of imperfections. The temperature increase during the adiabatic process promotes deformation localisation and instability. However, the stabilising effect of the strain rate sensitivity is dominating and leads to an increase of ductility with increasing strain rate similar to the super-plastic behaviour. On the other hand, increased strain rates reduce the local fracture strain leading to an increased dynamic notch sensitivity.

Résumé: L'influence de la vitesse de déformation sur la courbe contrainte-déformrion obtenue lors d'essais de traction par impact est discutée avec la théorie des imperfections. L'augmentation de température dans le domaine adiabatique favorise la localisation de la déformation et l'instabilité mécanique. Cependant l'effet stabilisant de la sensibilité à la vitesse de déformation est prédominant et conduit à une élévation de ductilité avec la vitesse de déformation, similaire à un comportement superplastique. Par ailleurs, l'augmentation de la vitesse de déformation diminue la valeur locale de l'allongement à la rupture conduisant à un accroissement de la sensibilité à l'effet d'entaille en dynamique.
\end{abstract}

\section{INTRODUCTION}

The influence of material parameters and deformation conditions on ductility and mechanical stability can be demonstrated by applying the theory of imperfections to the tension test. Small diameter deviations of a test bar are found to grow during the tension test leading to neck formation $[1,2]$. The local stress at the narrowest cross-section is first slightly higher than in other regions. With the beginning of the plastic deformation, the smallest diameter decreases more than the others. The strain hardening in the neck zone causes an increase of the force and acts stabilising on the deformation process. Under dynamic loading, four additional factors influence the ductility: the adiabatic character of the deformation processes promotes instability, since higher deformed regions are even more softened by the deformation heat. The increased strain rate sensitivity leads to an increase of the local value of the flow stress in the neck zone, so that other specimen regions undergo additional deformation. Mass inertia forces in the lateral direction arising due to reduction of area cause the initiation of either lateral tension or lateral compression stresses depending upon the time function of the specimen elongation. Last, the local failure strain decreases with increasing strain rate which means a higher notch sensitivity under impact conditions than under quasistatic loading.
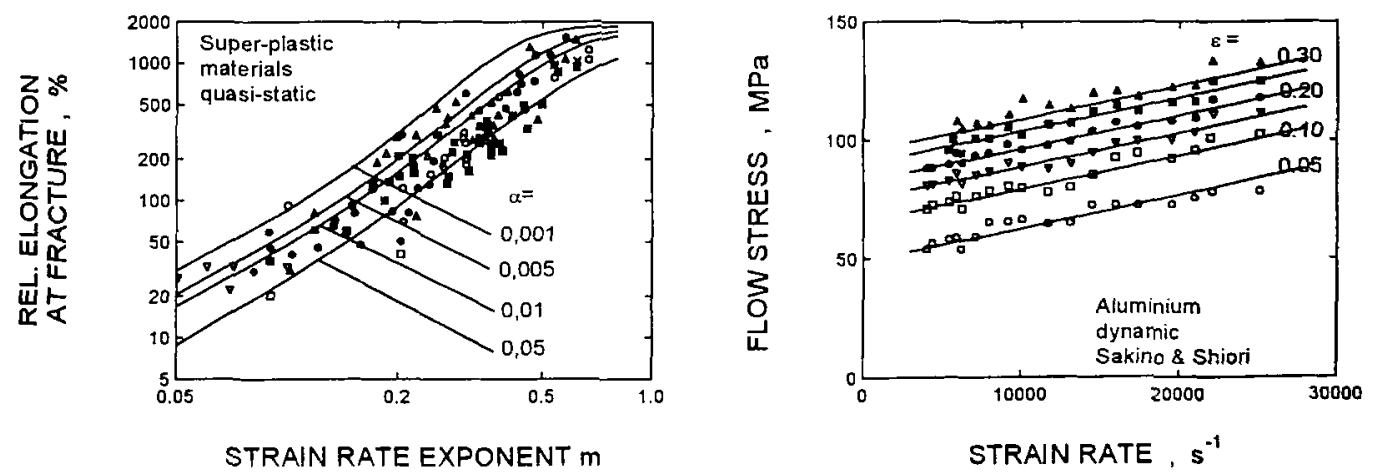

Figure 1: a) Relation between elongation at fracture and strain rate exponent $m=\hat{c} \ln \dot{\varepsilon} / \hat{c} \ln \sigma$ for different super-plastic materials, curves calculated with different values of the maximum deviation $\alpha$ of the cross-sectional area [4]

b) Strain rate dependency of flow stress: Experimental results of Sakino and Shiori for Aluminium [5] 
The common property of super-plastic materials is their high strain rate sensitivity $\mathbf{m}=\partial \ln \sigma / \partial \ln \dot{\varepsilon}$ hay. ing values higher than 0.3 . Figure 1 a shows the relation between the fracture elongation and $\mathrm{m}$ of different super-plastic materials cited in [3] and computation results [4] for bars with small nonuniformity of the cross-sectional area, distributed according to a cos-function along the specimen.

In case of strain rates higher than $2000 \mathrm{~s}^{-1}$, the damping mechanism dominates and the strain rate dependence of the flow stress is given by a linear relation $\sigma=\sigma_{\mathrm{h}}+\eta \dot{\varepsilon}$ as shown by experimental results of [5] in Figure $1 b$. For these results, a mean value of $\partial \ln \sigma / \partial \ln \dot{\varepsilon} \approx 0.2$ is determined, which lies below the values of super plastic materials. However, this value is high enough and would lead to an elongation at fracture of more than $100 \%$ according to Fig. la.

\section{INFLUENCE OF INCREASED STRAIN RATE SENSITIVITY}

The influence of strain rate can be studied quantitatively simply by considering a test bar, whose crosssectional area is not constant along the gauge length but is given by $\mathrm{S}_{0}=\mathrm{S}_{0_{\min }}[1+\alpha(\mathrm{x})]$ where $\alpha(\mathrm{x})$ can be represented by a parabolic function. The material behaviour is described by

$$
\sigma=\left[\mathrm{K}(\mathrm{B}+\varepsilon)^{\mathrm{n}}+\eta \dot{\varepsilon}\right] \exp \left[-\beta\left(\mathrm{T}-\mathrm{T}_{0}\right) / \mathrm{T}_{\mathrm{n}}\right]
$$

Assuming that $90 \%$ of the deformation energy is transferred to heat during a dynamic deformation process whereas the remaining $10 \%$ are consumed in increasing the internal energy e.g. due to dislocation multiplication, the temperature increases by $\mathrm{dT}=0.9 \sigma /\left(\rho_{\mathrm{d}} \mathrm{c}\right) \mathrm{d} \varepsilon$ where $\rho_{\mathrm{d}}$ and $\mathrm{c}_{\mathrm{m}}$ are the density and the specific heat of the material. With the temperature dependency of the flow stress according to eq.(la), temperature increase can be determined as a function of strain by integration and the stress-strain curve is then obtained for an adiabatic tensile test by substitution of the temperature in eq.(1a):

$$
\sigma_{\mathrm{ad}}=\frac{\mathrm{K}(\mathrm{B}+\varepsilon)^{\mathrm{n}}+\eta \dot{\varepsilon}}{1+\mathrm{a} \int\left[\mathrm{K}(\mathrm{B}+\varepsilon)^{\mathrm{n}}+\eta \dot{\varepsilon}\right] \dot{\varepsilon} \mathrm{dt}}
$$

with $\mathrm{a}=0.9 \beta /\left(\mathrm{T}_{\mathrm{n}} \rho_{\mathrm{d}} \mathrm{c}\right)$. As the force $F=\sigma_{a d} S_{0} \exp (-\varepsilon)$ is equal for all cross-sections, the strain $\varepsilon$ at an arbitrary cross-section can be determined as a function of the strain $\varepsilon_{1}$ at the minimum cross-section by a numerical evaluation of the relation

$$
\frac{\left[K(B+\varepsilon)^{n}+\eta \dot{\varepsilon}\right] \exp (-\varepsilon)}{1+a \int\left[K(B+\varepsilon)^{n}+\eta \dot{\varepsilon}\right] \dot{\varepsilon} d t}=\frac{S_{0 \min }}{S_{0}} \frac{\left[K\left(B+\varepsilon_{1}\right)^{n}+\eta \dot{\varepsilon}_{1}\right] \exp \left(-\varepsilon_{1}\right)}{1+a \int\left[K\left(B+\varepsilon_{1}\right)^{n}+\eta \dot{\varepsilon}_{1}\right] \dot{\varepsilon}_{1} d t}
$$

After reaching the maximum load, elastic unloading has to be considered for lower deformed regions.

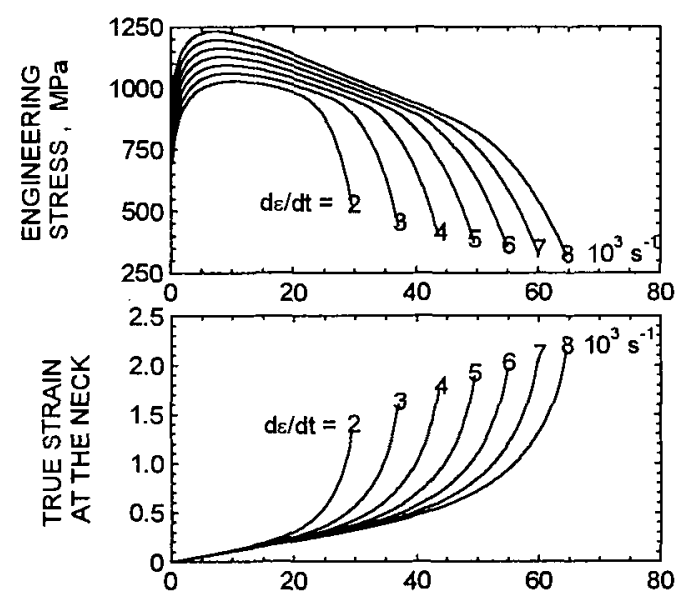

REL. ELONGATION OF SPECIMEN, \%

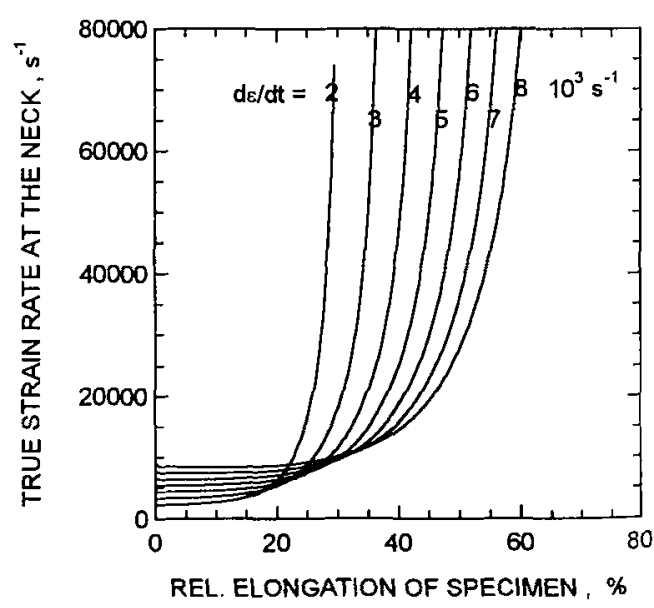

Figure 2: Computation results for a tensile specimen of $42 \mathrm{CrV} 6$ steel having a parabolic profile with a maximum diameter deviation of $2 \%$. 
The total extension of the specimen is calculated by integrating $[\exp (\varepsilon)-1]$ over the specimen length so that the relation between force and elongation can be calculated. Figure 2 shows calculation results for the conventional stress strain diagram of the low alloyed steel $42 \mathrm{CrV} 6$ determined for different strain rates. Especially after reaching the maximum load, the strain values corresponding to a defined value of force are increased. This simple model explains different phenomena observed in the dynamic tension test. Using a Split Hopkinson Tension Bar, the dynamic stress-strain diagrams were determined for tempered steel $42 \mathrm{CrV}$ 6, Armco-iron, Magnesium alloy and two Tungsten alloys (W16 and W00) and are compared in Figure 3 with the computation results obtained by the evaluation of eq.(2). It should be noted that the damping parameter $\eta$ depends slightly on strain. For the relatively high strain values at the neck zone, it was found that higher values of $\eta$ have to be chosen than those determined at the yield point.
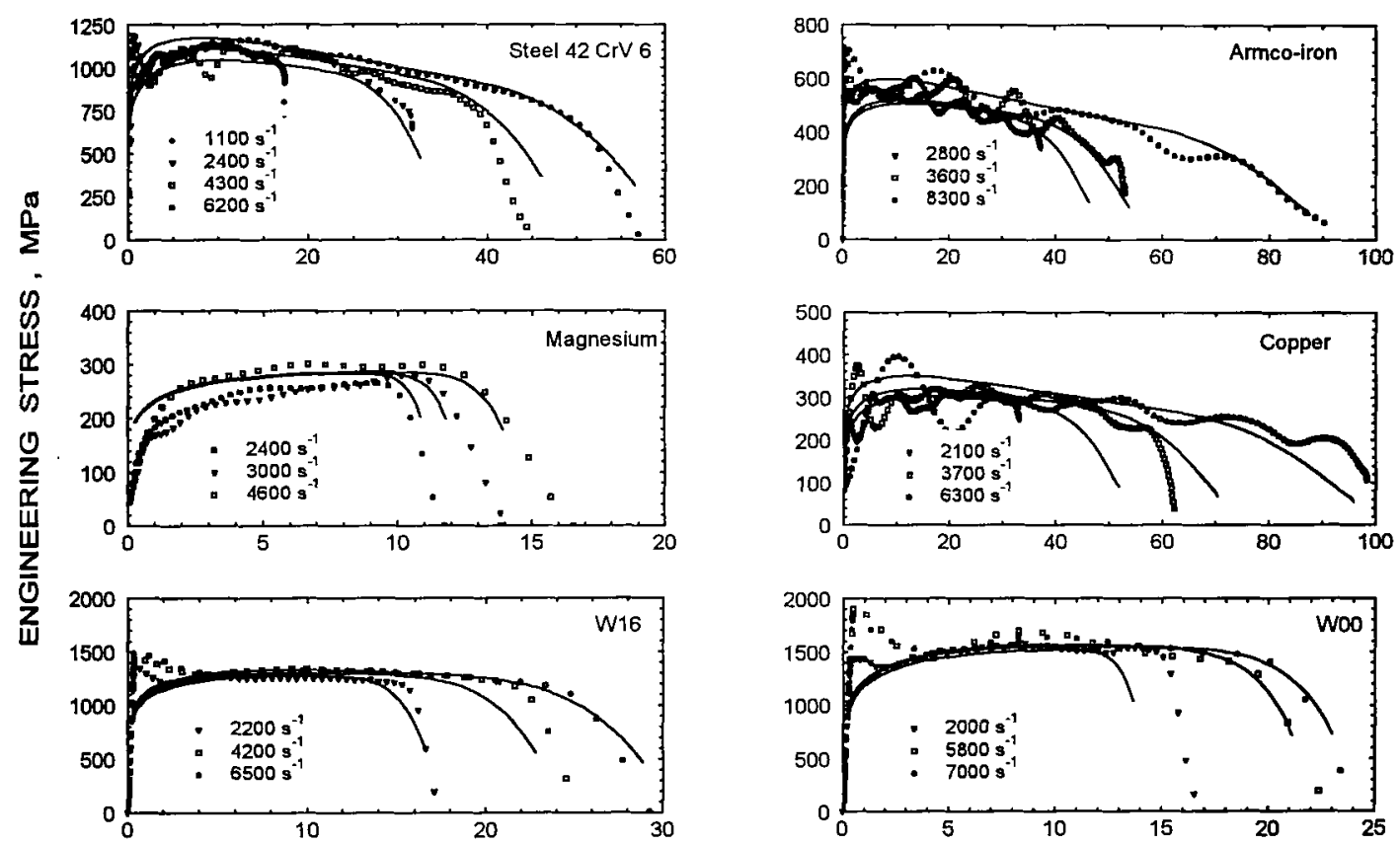

ENGINEERING STRAIN, \%

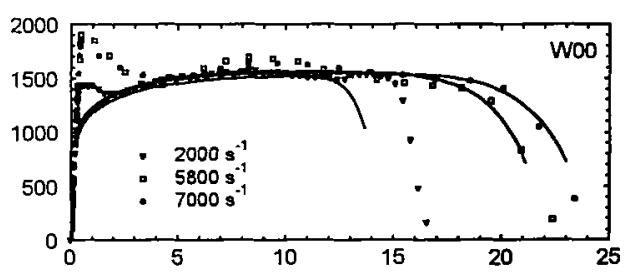

ENGINEERING STRAIN, \%

Figure 3: Influence of the strain rate on the stress strain curve, experimental results of the indirect impact tension test (marks) and computation results (curves)
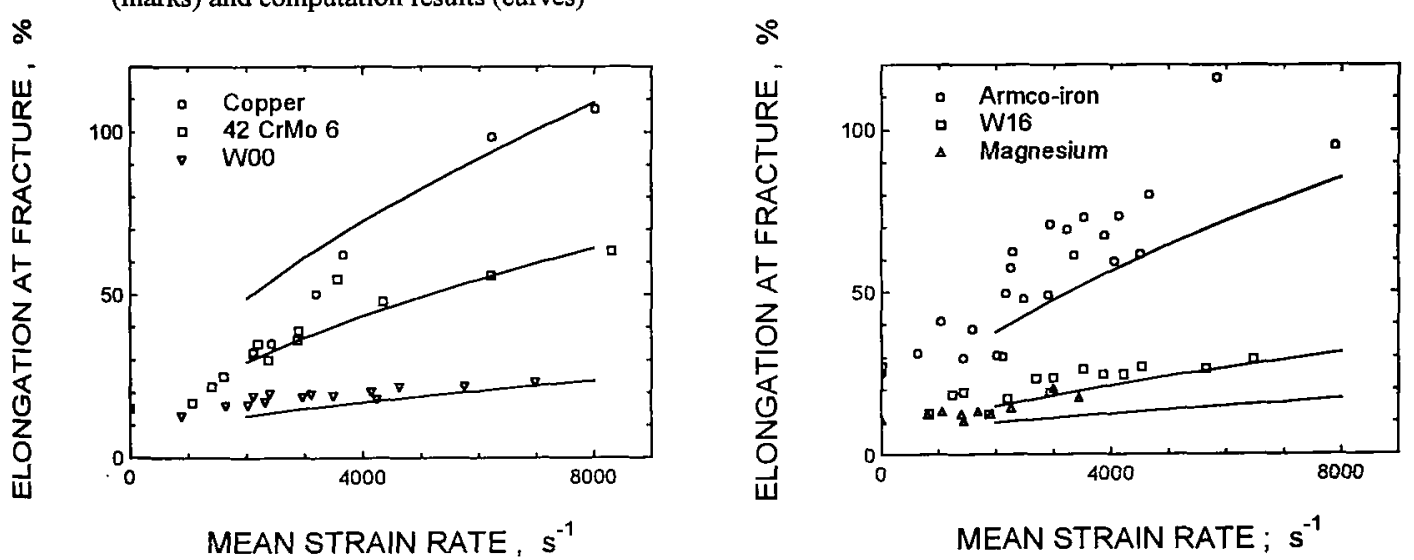

Figure 4: Influence of strain rate on the relative elongation at fracture: experimentai data (marks) and computation results (curves). 
Assuming that fracture takes place, as soon as an upper limit of the local strain is reached in the narrowest cross-section, the influence of strain rate on the elongation at fracture can be determined. Figure 4 shows experimental data and computation examples for this relation.

\section{REDUCED LOCAL FAILURE STRAIN}

In a previous investigation [6], the failure criterion was studied for high strain rate loading conditions where damping processes dominate. The failure criterion is usually defined by the local failure strain $\varepsilon_{\mathrm{f}}\left(\sigma_{\mathrm{m}} / \bar{\sigma}\right)$ as a function of the ratio between the mean stress $\sigma_{\mathrm{II}}=\left(\sigma_{\mathrm{I}}+\sigma_{\mathrm{II}}+\sigma_{\mathrm{II}}\right) / 3$ and the equivalent stress $\bar{\sigma}$. Such a criterion is deduced considering that ductile fracture occurs due to nucleation, growth and coalescence of micro-cavities [7], [8], [9]. The rate of void growth can be determined as a function of $\left(\sigma_{\mathrm{m}} / \bar{\sigma}\right)$ by applying the theory of plasticity. McClintock et al. [10] deduced a closed-form analytical so. lution for the rate-of-growth of cylindrical cavities of elliptical cross-section in a strain-hardening material. A more common relation was deduced Rice and Tracy [11] for the rate-of-change of the radius of a spherical void in an ideal plastic material

$$
\bar{\sigma}=\text { const.: } \quad \frac{1}{\mathrm{R}} \frac{\mathrm{d} \mathbf{R}}{\mathrm{d} \bar{\varepsilon}}=0.28 \exp \left[\frac{3 \sigma_{\mathrm{m}}}{2 \bar{\sigma}}\right]
$$

where $\mathbf{R}$ is the radius of an existing void and $\bar{\varepsilon}$ is the local equivalent strain. Hancock and Mackenzie [7] assumed the failure strain is given by the sum of two components: the strain up to the nucleation of voids $\varepsilon_{\mathrm{n}}$ which depends mainly on the degree of purity of the material, and the strain between void nucleation and fracture which is regarded to be inversely proportional to the relative rate of cavity growth with respect to strain $d \ln R / d \bar{\varepsilon}$ and introduced their well known failure criterion

$$
\varepsilon_{f}=\varepsilon_{n}+\alpha \exp \left[-\frac{3 \sigma_{m}}{2 \bar{\sigma}}\right.
$$

According to [12], the factor $3 / 2$ should be replaced by a material constant having usually higher values depending on the volume fraction of inclusions. Although this relation was deduced for ideal plastic, it was also applied to impact loading with highly increased strain rate sensitivity. Johnson and Cook [13] applied it after introducing correction factors considering the influences of strain rate and temperature:

$$
\varepsilon_{f}=\left[D_{1}+D_{2} \exp \left(-D_{3} \sigma_{m} / \bar{\sigma}\right)\right]\left[1+D_{4} \ln \left(\dot{\varepsilon} / \dot{\varepsilon}_{0}\right)\right]\left[1+D_{5} T / T_{m}\right]
$$

It is assumed that fracture starts when a damage parameter $\mathrm{D}=\Sigma\left(\Delta \varepsilon / \varepsilon_{\mathrm{f}}\right)$ reaches unity. As ductility usually increases with increasing temperature and the mechanical stability is increased by increasing strain rate sensitivity, it was expected, that the parameter $D_{4}$ and $D_{5}$ should be positive [13]. However, Barton et al $[14,15]$ showed that the failure strain of iron decreases when the strain rate or temperature increases. Assuming non-linear visco-plastic behaviour of a strain hardening and strain rate sensitive material, following relation was deduced [6]:

$$
\bar{\sigma}=\sigma_{h}+K \varepsilon^{n}\left(\overline{\dot{\varepsilon}} / \dot{\varepsilon}^{*}\right)^{m}: \quad \quad \frac{1}{R} \frac{d R}{d \bar{\varepsilon}}=\frac{1}{2}\left[\frac{3(m+n)}{2\left(1-f^{m+n}\right)} \frac{\sigma_{m}-\frac{2}{3} \sigma_{h} \ln (1 / f)}{\bar{\sigma}-\sigma_{h}}\right]^{1 /(m+n)}
$$

with $f$ approximately equal to the volume fraction of voids in the material. For impact loading with very high local values of the strain rate in the neck or at a notch root assuming pure viscous behaviour: 
$\bar{\sigma} \approx \eta \dot{\varepsilon}:$

$$
\frac{1}{R} \frac{d R}{d \bar{\varepsilon}} \approx \frac{3}{4(1-f)} \frac{\sigma_{m}}{\bar{\sigma}}
$$

Assuming that the failure strain is indirectly proportional to the relative rate of growth of the voids according to [7] and $\mathbf{f} \ll<1$, the failure criterion for a dynamic ductile fracture reads

$$
\bar{\sigma} \approx \eta \dot{\varepsilon}: \quad \varepsilon_{\mathrm{f}} \approx \varepsilon_{\mathrm{n}}(\dot{\varepsilon}, \mathrm{T})+\frac{\alpha}{\left(\sigma_{\mathrm{m}} / \bar{\sigma}\right)}
$$

In [6], indirect impact tensile tests were carried out on pure iron (Armco iron) and on the austenitic steel X2CrNiMo 1810 using a Split Hopkinson Tension bar arrangement. Notched specimens with different values for the notch radius of curvature $\rho$, root diameter $\mathrm{d}$ and outer diameter $\mathrm{D}$ were tested quasistatically and dynamically. In addition, hour-glass specimens having a circular profile line with a large radius of curvature were tested. The constants of the material low $\sigma=\mathrm{K}(\mathrm{B}+\varepsilon)^{\mathrm{n}}+\eta \dot{\varepsilon}$ were determined by testing cylindrical specimens. The time function of the particle velocity determined experimentally in the input bar was applied as a boundary condition in Finite Element computations using an explicit code for dynamic loading with lumped masses. The equivalent strain $\bar{\varepsilon}$ and the ratio $\left(\sigma_{\mathrm{m}} / \bar{\sigma}\right)$ were determined for different point along the radius of the specimen in the narrowest cross-section at different time points during the test and at fracture elongation. In case of hour-glass specimens, both of $\bar{\varepsilon}$ and $\left(\sigma_{\mathrm{m}} / \bar{\sigma}\right)$ are higher at specimen axis than at the surface. Therefore, it can be stated that in case of hour-glass specimens as well as in the neck zone of unnotched specimens, the fracture starts at the specimen axis. In case of notched bars the following fact could be stated: At the specimen axis the equivalent strain $\bar{\varepsilon}$ is lower, and the ratio $\left(\sigma_{\mathrm{m}} / \bar{\sigma}\right)$ is higher than at the surface of the notch. Therefore, the starting point of fracture is first unknown. Using the experimentally determined value for the total extension of the specimen at fracture, the corresponding values of $\bar{\varepsilon}$ and $\left(\sigma_{m} / \bar{\sigma}\right)$ were determined at different values of the radius in the narrowest cross-section and plotted in Figure $5 \mathrm{a}$ as a continuous curve for each specimen geometry.

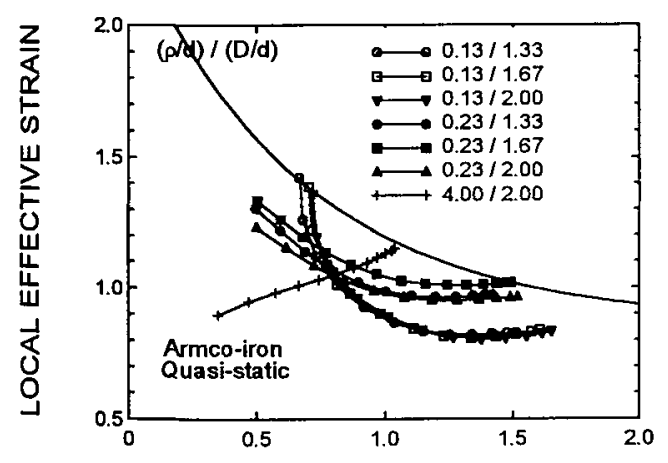

MEAN STRESS / EFFECTIVE STRESS

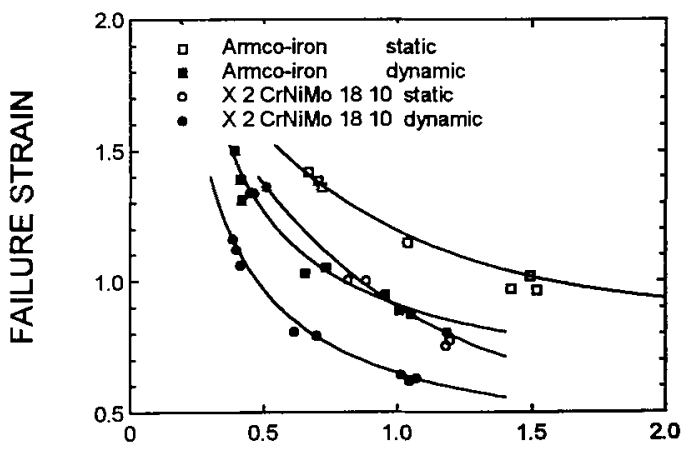

MEAN STRESS / EFFECTIVE STRESS

Figure 5: a) Local effective strain as a function of the ratio of the hydrostatic stress to the flow stress along the specimen radius at the narrowest cross-section, determined by FEM using the experimentally determined extension of the specimen at fracture

b) Failure criterion for ductile fracture under quasi-static and dynamic loading of iron and austenitic steel

Only one point of each curve fulfils the failure condition, while all other points of the curve show a local effective strain value which is still lower than the fracture strain $\varepsilon_{f}$ for the local value $\left(\sigma_{m} / \vec{\sigma}\right)$. Therefore, the upper envelope of the curves $\bar{\varepsilon}\left(\sigma_{m} / \bar{\sigma}\right)$ determined for specimens with different geometry 
represents the failure criterion $\varepsilon_{f}\left(\sigma_{m} / \bar{\sigma}\right)$. The point of contact between the envelope and the individual curve defines the location of the starting point of fracture. In case of relatively sharp notches, the envelope contacts the $\bar{\varepsilon}\left(\sigma_{m} / \bar{\sigma}\right)$ at higher values of $\bar{\varepsilon}$ and lower values of $\left(\sigma_{m} / \bar{\sigma}\right)$ which means that the fracture starts at the notch root. In case of relatively mild notches, the envelope contacts the $\bar{\varepsilon}\left(\sigma_{m} / \bar{\sigma}\right)$-curve at a point with higher values of $\left(\sigma_{m} / \bar{\sigma}\right)$ and lower values of $\bar{\varepsilon}$ indicating the starting point of fracture at the specimen axis. For the hour-glass specimens with great radius of curvature of the profile line, high values of $\bar{\varepsilon}$ coincide with high values of $\left(\sigma_{m} / \bar{\sigma}\right)$ at the specimen axis where fracture begins. These results are analogous to observations made under quasi-static loading [12].

The failure criteria obtained in this way are represented in Figure 9 for Armco-iron and for the technical austenitic steel X 2 CrNiMo 1810 under quasi-static and dynamic loading conditions. Contrary to the results obtained by Johnson and Cook [13], the local failure strain $\varepsilon_{f}\left(\sigma_{m} / \bar{\sigma}\right)$ determined here for Armcoiron and for steel $\mathrm{X} 2 \mathrm{CrNiMo} 1810$ under dynamic loading is much lower than that determined under quasi-static loading which is in agreement with the results of [14] for Remco-iron.

\section{CONCLUSIONS}

In the range of impact loading, the strain rate sensitivity increases with increasing strain rate reaching values near to those of super-plastic materials. As neck formation is accompanied by a local increase of strain rate, the strain rate sensitivity acts stabilising on the deformation process. This effect is dominant compared with the destabilising effect of the stress reduction caused by the temperature increase during the adiabatic impact deformation. However, the sensitivity for notches increases with increasing strain rate. Under dynamic loading, an increased ductility with high values of elongation at fracture can only be expected for smooth bars of pure materials. The local failure strain is not only a function of the ratio between the mean stress and the effective stress. It depends also on the local value of the strain rate. The strain at which voids are nucleation around inclusions is dependant on strain rate and decreases seriously when the load is applied dynamically.

\section{References}

[1] El-Magd, E.: Materialprüfung 15(1973)p. 90-95

[2] El-Magd, E.: Archiv Eisenhüttenwesen 45(1974)p.83-89

[3] Rassman, G.; Müller, P.; Grabner,W.: Neue Hütte 17(1972) No.8, p. 449-454

[4] Troost,A.; El-Magd, E.: Materials Science \& Engineering 28(1977) pp.201-207

[5] Sakino,K; Shiori, J.: Journal de Physique IV, Colloque C3-35, suppl. III, Vol. 1, Oct. 1991

[6] El-Magd, E.: Steel research 68(1997) No.2, pp. 67-71

[7] Hancock, J.W.; Mackenzie, A.C.: J. Mech. Phys. Solids, 24(1976) p. 147-169

[8] Needleman, A.; Tvergaard, V.: J. Mech. Phys. Solids 32(1984) p. 461-490

[9] Tvergaard, V.; Needleman, A: J. Mech. Phys. Solids 34(1986)pp. 213-241

[10] McClintock, F.A.: J.appl.Mech. 35(1968)pp.363.

[11] Rice, J.R.; Tracy, D.M.: J. Mech. Phys. Solids, 17(1969) p. 201-217

[12] Holland, D.; A. Halim; Dahl, W.: Steel research 61(1990), p. 504-506

[13] Johnson, G.R.; Cook, W.H.: Eng. Fract. Mech. 21(1985), p. 31-48

[14] Barton, D.C.; J.L. Sturges; M.S. Mirza; Church, P.: Journal de Physique IV, Colloque C3-931, suppl. III, Vol. 1, Oct. 1991

[15] Barton, D.C.; M.S. Mirza; J.L. Sturges; Waheed, M.: Journal de Physique IV, Colloque C8-659, suppl. au J. de Physique III, Vol. 4, Sept. 1994 